\title{
Collection building amongst heritage amateurs
}

Roued-Cunliffe, Henriette

Published in:

Collection and Curation

DOI:

10.1108/CB-01-2017-0003

Publication date:

2017

Citation for published version (APA):

Roued-Cunliffe, H. (2017). Collection building amongst heritage amateurs. Collection and Curation, 36(3), 108114. https://doi.org/10.1108/CB-01-2017-0003 


\section{eemeraldinsight}

\section{Collection Building}

Collection building amongst heritage amateurs

Henriette Roued-Cunliffe,

\section{Article information:}

To cite this document:

Henriette Roued-Cunliffe, (2017) "Collection building amongst heritage amateurs", Collection Building, Vol. 36 Issue: 3 , pp.108-114, https://doi.org/10.1108/CB-01-2017-0003

Permanent link to this document:

https://doi.org/10.1108/CB-01-2017-0003

Downloaded on: 01 March 2018, At: 01:35 (PT)

References: this document contains references to 43 other documents.

To copy this document: permissions@emeraldinsight.com

The fulltext of this document has been downloaded 225 times since 2017*

\section{Users who downloaded this article also downloaded:}

(2017),"Diversity at work in academic libraries 2010-2015: an annotated bibliography", Collection Building, Vol. 36 Iss 3 pp. 89-95 <a href="https://doi.org/10.1108/CB-12-2016-0038">https://doi.org/10.1108/CB-12-2016-0038</a>

(2017),"Relationship between budget allocation and growth of resources at the university libraries of Northern India - a study", Collection Building, Vol. 36 Iss 3 pp. 127-134 <a href="https://doi.org/10.1108/CB-01-2017-0005">https://doi.org/10.1108/

CB-01-2017-0005</a>

Access to this document was granted through an Emerald subscription provided by emerald-srm:292919 []

\section{For Authors}

If you would like to write for this, or any other Emerald publication, then please use our Emerald for Authors service information about how to choose which publication to write for and submission guidelines are available for all. Please visit www. emeral dinsight. com/ authors for more information.

\section{About Emerald www.emeraldinsight.com}

Emerald is a global publisher linking research and practice to the benefit of society. The company manages a portfolio of more than 290 journals and over 2,350 books and book series volumes, as well as providing an extensive range of online products and additional customer resources and services.

Emerald is both COUNTER 4 and TRANSFER compliant. The organization is a partner of the Committee on Publication Ethics (COPE) and also works with Portico and the LOCKSS initiative for digital archive preservation.

*Related content and download information correct at time of download. 


\title{
Collection building amongst heritage amateurs
}

\author{
Henriette Roued-Cunliffe \\ Royal School of Library and Information Science, University of Copenhagen, Copenhagen, Denmark
}

\begin{abstract}
Purpose - The purpose of this paper is to gather an overview of different research fields that study collection building amongst heritage amateurs (e.g. amateur archaeologists, family and local historians, etc.).

Design/methodology/approach - First, the paper will define the term heritage amateur and then identify possible fields in which these groups and their collection building have been studied. A snowball procedure was used to collect material for the study.

Findings - While there is an overlap between some of the subjects and fields examined, there is a potential for more collaboration resulting in a deeper understanding of collection building amongst heritage amateurs.

Research limitations/implications - The term heritage amateur is not widely used, and the identification and collection of material for the review rely on the definition and understanding of this term and the groups included under it.

Practical implications - This review of existing literature will benefit researchers and practitioners in the fields of education, information science, museums, libraries and archival studies, as well as the multidisciplinary area of heritage studies.

Social implications - There is a growing institutional and political interest in making digital heritage collections available to the general public, and this paper argues that an important part of this is understanding how heritage amateurs already do this.

Originality/value - This paper will connect narrow interest areas such as participatory heritage or serious leisure and show how their angles on heritage amateurs differ and compare.
\end{abstract}

Keywords Information behaviour, Cultural heritage, Amateurs, Community groups, GLAM institutions, Participatory heritage

Paper type Literature review

\section{Introduction}

The field of collection building and information science is becoming increasingly aware of the needs of cultural heritage in relation to digitisation, preservation of born-digital cultural material and the discourse on heritage taking place on online platforms. The newly initiated EU COST network, ARKWORK[1], is a collaboration between information scientists and archaeologists, with the aim at understanding how archaeological knowledge is produced and used in a digital context. The edited volume on Cultural Heritage Information (Ruthven and Chowdhury, 2015) examines current research and development in relation to the creation, access and management of digital heritage information. However, as in information science, much of what is done within this field focuses on organisations and professionals as well as education. As has been argued for the field of everyday life information seeking (ELIS) (see below), collection building and information behaviour of amateurs in relation to cultural heritage is just as relevant as that of professionals, as it can give us an understanding of a more intuitive approach to these subjects.

Heritage amateur as a term is not well defined nor widely used. It is, however, an appropriate way of describing a group

The current issue and full text archive of this journal is available on Emerald Insight at: www.emeraldinsight.com/0160-4953.htm

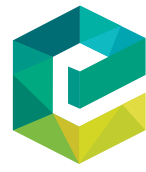

Collection Building

36/3 (2017) 108-114

(C) Emerald Publishing Limited [ISSN 0160-4953]

[DOI 10.1108/CB-01-2017-0003] of people who have an amateur interest within the scope of heritage. To fully understand the term and what is meant by it, we must have a clear understanding of the two parts: heritage and amateur. This literature review will first define heritage amateurs and then explore literature on collection building and information behaviour in relation to three different groups that can be understood as heritage amateur: amateur archaeologists and metal detectorists, family historians/ genealogists and local/community historians. Despite a growing interest in this subject[2], there is no research field established around it yet. This paper will do a literature review on this subject within five relevant research fields: serious leisure perspective, everyday life information seeking, personal information management, crowdsourcing and participatory heritage. The paper used a snowballing procedure (Wohlin, 2014) as a method for gathering literature about these subjects that is relevant to the concept of heritage amateurs and collection building. The start set used keywords from the groups and subjects mentioned above as well as synonyms. For example, when searching for heritage, keywords such as history, museums, archives, libraries are included. The literature found through this process forms the start set which sets the snowball rolling. The next step used the citations in these papers and books to find more relevant material.

\section{Understanding heritage amateurs}

The interest in heritage has grown according to Bagnall (2009; pp. 105-106), who talks about a "heritage boom" in Britain since the 1970s. This interest can furthermore be seen on a global scale with the UNESCO convention of 1972 . UNESCO's understanding of heritage has over the years 
developed from monuments, buildings and sites (UNESCO WHC, 1972; Article 1) to the inclusion of other tangible (e.g. paintings, manuscripts, shipwrecks) and intangible (e.g. oral traditions, performing arts, rituals) heritage (UNESCO, 2016). There is no consensus between nations on the understanding of cultural heritage, which depends greatly on the cultural traditions of each country or culture (Ahmad, 2006). Furthermore, the definition of cultural heritage can and does have implications on what is preserved, who will preserve it and how it will be preserved (Alzahrani, 2013), often leaving the heritage of marginalised groups unpreserved (Borgen et al., 2016). In the context of this paper, heritage is defined as any tangible or intangible concept or object that has cultural significance now or in the future. This is necessarily a very wide definition which aims to be inclusive of all cultures and traditions.

The term amateur has a somewhat different and less legal background with diverging definitions. Amateur comes from the Latin word ămātor, meaning a lover or a friend (Lewis and Short, 1879). The Oxford English Dictionary defines amateur back to 1784 as "one who loves or is fond of" something or as an opposition to a professional, sometimes disparagingly (OED Online, 2016). Being an amateur has long had this duality between doing something out of love or passion and without pay on the one hand and doing something less skilled (Paulos, 2012). However, in the current Oxford Living Dictionaries the definition is lacking the concept of love and is merely defined as a non-professional and/or someone who is contemptibly inept (Oxford Living Dictionaries, 2016). Under all circumstances, the term is closely linked to the idea of a professional. In the Sage Dictionary of Leisure Studies, Crawford describes this development as related to the contemporary idea of professionalism being associated with expertise rather than the Victorian class based division between gentlemen amateurs and working-class professionals. Crawford notes that the term is commonly associated with "engaging in an activity without formal payment and/or having received no formal training" (Crawford, 2009, p. 8), and this understanding will be used in the following.

Therefore, the term heritage amateurs is understood as a group of people who work in a manner that is unpaid, untrained and interest driven with both tangible and intangible concepts or objects that are culturally significant in a long-term perspective.

I believe it is currently highly relevant to study this group of people for their potential to act as ambassadors and innovators for a heritage sector, which in many parts of the world is struggling to sustain relevance in the public and political eye and following on from that has issues with funding.

The following will review literature on specific, well-defined groups of heritage amateurs which are known to not only take an active unpaid interest in heritage but also engage in a manner of collection building.

\section{Amateur archaeologists and metal detectorists}

Amateur archaeologists are a community of people who work as archaeologists without formal pay and/or formal training. Despite being routinely left out in current histories of archaeology, the women and men that make up amateur archaeology have a long history that extends back to before the institutionalisation and professionalisation of the field. These people were, and are, instrumental for the popular dissemination of archaeological knowledge and their invisibility in particular affects our understanding and appreciation of early female archaeologists (Díaz-Andreu García and Sørensen, 2011, p. 13, 18). Beale et al. (2017, p. 174) stress the importance of re-engaging community members in the recording and management of burial spaces in the UK to counteract the risk they face as heritage objects.

Another related concept to amateur archaeology is the hobby of metal detecting, which de Groot (2009, p. 65) describes as a "traditional way for under-educated - mainly male, mainly working class - members of the public" to get involved with the discovery of portable antiquities. Sometimes looked down upon by professional archaeologists as treasure hunting, it can nonetheless be a vital contribution to archaeological knowledge, especially if finds are registered and a code of practise is upheld (Dobat, 2013). In 1999, the UK established an online database known as Portable Antiquities Scheme (PAS) (www.finds.org.uk) with the aim to build a collection of archaeological artefacts and, most importantly their context, that were found outside the sphere of professional archaeology and thus in many circumstances would never have been registered (The British Museum, 2016). Very few countries in the world have such systems in place to preserve archaeological knowledge from the amateur sphere and in comparison, in the US metal detecting is a much more object-driven competitive pastime which has little contact to heritage institutions.

\section{Family historians/genealogists}

Yakel (2004) differentiates between genealogists, as those who study ancestry and descent, and family historians, as those who study the narrative of events in their ancestors lives. However, she acknowledges that the terms are also used interchangeably and some even use genealogist to denote a professional in this field. Genealogy has become one of the most popular heritage-related activities in the world (de Groot, 2009, pp. 73-74), and the internet has certainly fuelled family history research in the way it facilitates both individual and collaborative collection building and knowledge sharing across great distances, socially and geographically (Bishop, 2005, p. 991). De Groot uses Chris Rojek's (2005) “active consumption" model of the internet to understand genealogical websites rather than viewing this consumption of history as passive (de Groot, 2009, pp. 75-76).

Genealogy is a hobby that is driven by the desire to detect the story of where we came from, both as an identity project to personalise history and as a part of a contemporary anxiety over a fragmentation of traditional structures (de Groot, 2009, pp. 73-76). "Identifying, selecting, documenting, and organizing information are integral components of genealogical work" (Yakel, 2004). Bishop (2005, p. 1005) views genealogy as a subject comparable to collecting and journalism in that all gather information to be used for the telling or retelling of a story. Collection building within family history often begins with the gathering of memories and memorabilia from older relatives (de Groot, 2009, p. 74). The next step involves collecting information on individual family members from official sources to create a structure or a family 
tree. Often digital technology facilitates this through database systems that can register individuals, events, dates, places, sources and of course relationships between individuals. It is a form of "expanded information seeking served as a means of learning about the historical narrative more broadly and at the same time filling in the personal story of their ancestor's life" (Yakel, 2004). At some point in this process, many family historians wish to add meat to the bones of the family tree by including in their collection, knowledge about the people, their occupation, daily lives, notoriety, etc. At this point, the genealogist must learn to think archivally and gain skills and knowledge in palaeography and dating methods (de Groot, 2009, p. 76).

\section{Local/community historians}

Community historians, local historians, keepers of history are some of the many names for a group of people who take an active interest in preserving and communicating their local community's history for the future. According to de Groot (2009, p. 62), it is closely linked to the expansion of adult education after the Second World War. He suggests on the one hand that local historians have a preoccupation with the decline of local communities as a reaction to the fragmentation of the world, understood as modernity and globalisation. On the other hand, he acknowledges that the "[k]ey to the phenomena of local history is a sense of the importance of personal interest and fulfilment" (de Groot, 2009 , p. 63) much like is the case with family history.

Customs and opportunities differ around the world, but in many places, cultural institutions such as libraries, archives and museums take an active part in working, aiding and providing facilities and tools to these community historians (Copeland and Barreau, 2011, p. 638). Some have in turn criticised heritage institutions, in this case US libraries, for serving mainstream interests in their preservation and acquisition processes over local and diverse community interests (Danky, 1996). After the millennium, there has been a boom in the interest in local history in popular media and the demand for books and instructions on how to get involved (de Groot, 2009, p. 64).

\section{Research fields}

Collection building is in itself a wide subject and in terms of heritage it is often dealt with in the professional context of gallery, library, archive and museum (GLAM) institutions. However, some research fields do tangent or even overlap into the subject of collection building amongst heritage amateurs. The following will review literature related to this subject in both newer and more established research fields.

\section{Serious leisure perspective}

The serious leisure perspective (SLP) as a social science field builds on Stebbins (1979) original work on amateurs from 1974. His motivation was the lack of definition of amateur which he then set out to understand and ended up framing as a part of serious leisure. His work on amateurs is ground breaking in that it does not describe or understand the activities themselves but instead looks at the amateur practitioners of various activities such as theatre, archaeology and baseball to understand what they have in common as amateurs and what sets them aside from professionals. His focus as a social scientist was on collective amateur activities and the effects of social interaction therein.

In 1982, he formulated his conceptual statement of serious leisure as a counterpart to casual leisure [e.g. play, relaxation, entertainment (Stebbins, 1982)]. The SLP encompasses the systematic pursuit of amateurs, hobbyists and volunteers. Amateur activities are further classified as art, entertainment, sports and science. Heritage amateurs would in this sense fall under science and in the North American context under social sciences as history and archaeology amateurs in particular. Among science amateurs Stebbins further identifies three kinds of participants: observers who experience their objects through scientific inquiry; armchair participants who pursue their interest through reading; applied scientists who work practically by, for example, collecting scientific data. For science amateurs, the core activities are thus reading and collecting descriptive data. Stebbins research has shown that the amateurs' level of knowledge and contribution to original data collection varies much more than that of their professional counterparts and thus describes them as apprentices, journeymen or masters. The advancement between these stages is however inexact (Elkington and Stebbins, 2014, pp. 62-64).

\section{Everyday life information seeking}

ELIS is a field of research related to human information behaviour (HIB) with a specific focus on the everyday life rather than professional life (Savolainen and Kari, 2004). This includes studies of information behaviour and collection building in regards to hobbies such as family history (Yakel, 2004) or museum visitors (Skov, 2013). As with collection building, research into information seeking has typically been focused on the professional sphere with surveys into job-related information behaviour (Savolainen, 1995). Savolainen, the originator of ELIS, focuses on information seeking approaches and offers a framework that includes way of life and mastery of life. Way of life can be understood as the order of things or rather the choices and prioritisation made between activities that are not job related, such as amateur activities. Mastery of life can be either active or passive and is based on one's values, which again is related to a person's social class and/or generation and which provide a natural order that can be perceived as self-evident (Savolainen, 1995). Hartel has opened up a path of research which draws on ELIS and SLP to examine collection building and information management within the leisure pursuit of cooking (Hartel, 2010). Hartel identifies a personal culinary library, which can take different shapes and sizes and which is an essential part of culinary hobbies for many practitioners. She suggests that this personal library is also present in many other hobby pursuits.

\section{Personal information managing}

The field of personal information management (PIM) examines "finding, keeping, organizing, and maintaining information" (Jones, 2008; Chapter 1) and can be summed up as "keeping found things found" (Jones, 2008; 
Chapter 1). PIM like HIB examines both the everyday and job-related information management, and Jones describes PIM as both a field of study and a practise. Therefore, it is in essence not related to heritage amateurs as such. However, personal archiving studies have shown that while the growing amounts of digital material collected by most people is being saved and backed up it is not being archived in a traditional sense. This is something that Boardman and Sasse (2004) believe would be beneficial and this in turn has led Copeland and Barreau (2011, p. 638) to develop the Co-Created Community Repository Framework. It is here that heritage amateurs come into play, as one of the three community components in this framework is community residents, who have personal collections they wish to preserve digitally. Libraries play a large role in this as they "have traditionally made material available to those who can least afford it" (Copeland and Barreau, 2011, p. 645) and are in Copeland and Barreau's view, in the ideal position to encourage appreciation of personal heritage artefacts and to aid in the building of collections around this.

\section{Crowdsourcing}

Crowdsourcing within the context of heritage information is typically a way for GLAM institutions to outsource collection building to the general public. Ridge (2014) has edited a volume titled Crowdsourcing our Cultural Heritage, which draws upon experience with and research in crowdsourcing heritage from around the world. The chapters draw from experience with many large projects where crowdsourcing has been used as a method for digitising large collections (Ridge, 2014, p. 1), for example, the manuscripts of philosopher and reformer Jeremy Bentham (Causer and Terras, 2014) or historic ships logs as a part of the Old Weather project (Blaser, 2014). Along with Wikipedia and FamilySearchIndexing, Trove, which provides access to heritage collections across Australia[3], is an often-cited crowdsourcing project which has provided much insight into the how and why of user involvement. Trove is hosted by the National Library of Australia who has been particularly active in trying to understand the motivations of those engaged in crowdsourcing activities such as correcting imperfect OCR'd newspaper text (Ayres, 2013). These findings show that the amount of volunteers' work is shaped as a long-tailed distribution with few users (10 per cent) doing most of the work (up to 80 per cent) and a large part of the users doing decreasingly little work. The very active volunteers are engaging with the crowdsourcing project as if it were a full-time job (Holley, 2010) and they can be likened to Elkington and Stebbins' (2014) concept of a leisure career in volunteering. These super users vary in age but most are either retired or young, dynamic, high achieving professionals as such with full-time jobs, and the latter usually take on moderating roles. About half the volunteers can be seen as heritage amateurs with a particular interest in the subject matter [typically family historians (Ridge, 2017)], whereas the other half do it because they see it as a good cause (Holley, 2010). Typically, calls for participants for crowdsourcing projects go out to the general public, with the idea that the projects can act as a learning experience and even those with little knowledge can contribute something valuable over time. However, there is another type of crowdsourcing that focuses on experts with domain knowledge in the subject-matter, also called nichesourcing. De Boer et al. (2012) compares crowdsourcing to nichsourcing on three different parameters:

1 Crowdsourcing tasks are simple where nichesourcing tasks are knowledge-intensive.

2 Crowdsourcing products are determined by quantity where nichesourcing products are determined by quality.

3 The crowdsourcing resource pool is a large, anonymous and heterogeneous crowd, whereas the nichsourcing resource pool is a community of interest or practice of people who have a certain skill or expertise (de Boer et al., 2012).

There are many reasons for GLAM institutions to develop crowdsourcing projects, enhanced digital collection building being one. However, the future is getting the public involved in heritage research of their own (Nourse et al., 2017), and this is probably why crowdsourcing and nichesourcing appeals to so many family historians who are already involved with their own heritage research.

\section{Participatory heritage}

The work with participatory heritage is derived from the idea of participatory culture and the participatory museum. Participatory culture has "relatively low barriers to artistic expression and civic engagement, strong support for creating and sharing creations, and some type of informal mentorship whereby experienced participants pass along knowledge to novices" (Jenkins et al., 2009, p. 11). The participatory museum (Simon, 2010) provides models for participation in museums with examples taken from other GLAM institutions. Like crowdsourcing, participation in museums serves several different goals, amongst them are goals set by the institution. Simon mentions that " $[\mathrm{m}]$ any cultural professionals are more familiar with providing visitor experiences than thinking about how visitors can usefully contribute to the institution" (Simon, 2010, p. 13). Nevertheless, heritage amateurs can be understood as a group of people who have much value to offer heritage institutions from funding (directly through crowdfunding and donating or indirectly through public funding that relies of visitors and public interest) to knowledge, expertise and a passion for the subject at hand.

The edited volume Participatory Heritage (Roued-Cunliffe and Copeland, 2017) examined a variety of heritage participants from amateur archaeologists to community historians from schools to Wikipedia editors. Through these case studies, it is clear that participatory heritage comes with challenges as well as solutions. One challenge in relation to collection building amongst heritage amateurs in particular is respect. Respect especially for historically marginalised communities, their heritage material and their right to find their own space in a mainstream history understanding. The idea of participatory heritage and the many projects attempting to put this into play usually put respect for participants, their skills and expertise and their 
heritage in forefront when it comes to not only building but also managing and using collections.

\section{Conclusion}

This paper has identified a growing interest in heritage amateurs and collection building with and amongst them from different directions, which has motivated this literature review as an attempt to find common ground. First, the paper defines heritage amateurs as people who take an active unpaid interest in tangible or intangible culturally significant concepts or objects. This is followed by examining three heritage amateur groups and their engagement in collection building:

1 Amateur archaeologists and metal detectorists work to discover ancient artefacts and schemes like the British PAS work to collect the knowledge generated by these endeavours.

2 Family historians and genealogists gather information about their ancestors which they often collect and manage in some form of digital repository. This information can be in the form of metadata (e.g. dates, places, names), text (e.g. wills, diaries) and photos.

3 Local and community historians are often connected to some sort of GLAM institution, whether publicly or privately funded and with or without heritage information professionals. Their collections are therefore often stored and managed as institutional repositories with varying degrees of standardisation.

In terms of collection building amongst heritage amateurs, this paper looks to other more and less established research fields to find theories and models that can aid the understanding of this field. This literature review has identified five such fields:

1 The SLP is shaped by ground-breaking sociological work on amateurs which has developed into an intricate model of leisure activities. In this case, science amateurs are of particular interest, and Stebbins provides detailed insights into their development in terms of levels of knowledge and contributions to original data collection.

2 ELIS is a part of information behaviour research that focuses on non-work and non-education and sometimes more specifically on hobbies like family history or museum visitors. Here, Hartel has amongst others examined collection building albeit related to culinary hobbies.

3 PIM focuses on the task of keeping found things found by encouraging people to learn the skills of archiving and building collections of their own cultural artefacts with the aid of libraries.

4 Crowdsourcing is centred around mass collection building by involving the public in smaller tasks, which each amass into large collections. Another variant is nichesourcing which involves users with domain knowledge, such as family historians who often are skilled readers of handwritten texts, in small-scale but more knowledge-intensive collection building.

5 Finally, participatory heritage is a newer field that builds on the concept of participatory culture and participatory museums and has a particular focus on the
Volume $36 \cdot$ Number $3 \cdot 2017 \cdot 108-114$

participatory aspect as well as the participants in heritage when it comes to collection building.

While carrying out this review of literature relevant to the subject of collection building amongst heritage amateurs, it was revealed that some fields overlap considerably, such as the hobby of family history with research fields such as ELIS and crowdsourcing, ELIS with PIM or amateur archaeologists and SLP. However, there are other fields and subjects that do not seem to converge, where I believe such a meeting would be beneficial for both parties, such as SLP which could supply some interesting perspectives on the subject of leisure careers in crowdsourcing, or participatory heritage which could provide a better understanding of amateur archaeology and local history around the world.

\section{Notes}

1 Available at: www.arkwork.eu/about/

2 See, for example, the ARKWORK work Group 3: Archaeological knowledge production and global communities, www.arkwork.eu/working-groups/workinggroup-3

3 Available at: http://rove.nla.gov.au/general/about

\section{References}

Ahmad, Y. (2006), "The scope and definitions of heritage: from tangible to intangible", International fournal of Heritage Studies, Vol. 12, pp. 292-300, doi: 10.1080/ 13527250600604639.

Alzahrani, D.A. (2013), "The adoption of a standard definition of cultural heritage", International fournal of Social Science and Humanitv, Vol. 3 No. 1, pp. 9-12, doi: 10.7763/ IJSSH.2013.V3.182.

Ayres, M.L. (2013), "Singing for their supper: trove, Australian newspapers, and the crowd", Presented at the IFLA WLIC 2013, Singapore, available at: http://ibrary. ifla.org/245/1/153-ayres-en.pdf

Bagnall, G. (2009), "Heritage", in Blackshaw, T. and Crawford, G. (Eds), The SAGE Dictionary of Leisure Studies, SAGE, Los Angeles; London, pp. 105-106.

Beale, G., Smith, N. and St Mary the Virgin Embsay with Eastby Churchyard survey team (2017), "New approaches to the community recording and preservation of burial spaces", in Roued-Cunliffe, H. and Copeland, A.J. (Eds), Participatory Heritage, Facet Publishing, London, pp. 173-194.

Bishop, R. (2005), “The essential force of the clan: developing a collecting-inspired ideology of genealogy through textual analysis", The fournal of Popular Culture, Vol. 38 No. 6, pp. 990-1010.

Blaser, L. (2014), "Old weather: approaching collections from a different angle", in Ridge, M. (Ed.), Crowdsourcing Our Cultural Heritage, Digital Research in the Arts and Humanities, Ashgate, Farnham, Surrey.

Boardman, R. and Sasse, M.A. (2004), Stuff goes Into the Computer and Doesn't Come Out: A Cross-Tool Study of Personal Information Management, ACM Press, New York, NY, pp. 583-590, doi: 10.1145/985692.985766. 
Borgen, M., Thylstrup, N.B. and Veel, K. (2016), "Introduction: theme, gender and crowdsourcing", Nordisk Tidsskrift for Informationsvidenskab og Kulturformidling, Vol. 5, pp. 3-8.

Causer, T. and Terras, M. (2014), "Many hands make light work. many hands together make merry work: transcribe bentham and crowdsourcing manuscript collections", in Ridge, M. (Ed.), Crowdsourcing Our Cultural Heritage, Digital Research in the Arts and Humanities, Ashgate, Farnham, Surrey.

Copeland, A.J. and Barreau, D. (2011), "Helping people to manage and share their digital information: a role for public libraries", in Marty, P.F. and Kazmer, M.M. (Eds), Involving Users in the Co-Construction of Digital Knowledge in Libraries, Archives, and Museums, Johns Hopkins University Press, Baltimore, MD, pp. 637-649.

Crawford, G. (2009), "Amateur and amateurism", in Blackshaw, T. and Crawford, G. (Eds), The SAGE Dictionary of Leisure Studies, SAGE, Los Angeles, London, pp. 8-9.

Danky, J.P. (1996), "Libraries: they would have been a good idea", Alternative Library Literature: A Biennial Anthology, pp. 3-6.

De Boer, V., Hildebrand, M., Aroyo, L., De Leenheer, P., Dijkshoorn, C., Tesfa, B. and Schreiber, G. (2012), "Nichesourcing: Harnessing the power of crowds of experts", in Teije, A. (Ed.), Knowledge Engineering and Knowledge Management, 18th International Conference, EKAW Proceedings, Galway Citv, 8-12 October, Springer, Berlin, New York, pp. 16-20.

De Groot, J. (2009), Consuming History: Historians and Heritage in Contemporary Popular Culture, Routledge, London; New York, NY.

Díaz-Andreu García, M., Sørensen, M.L.S. (2011), "Excavating women", in Díaz-Andreu García, M. and Sørensen, M.L.S. (Eds), Excavating Women: A History of Women in European Archaeology, Routledge, London, pp. 1-30.

Dobat, A.S. (2013), "Between rescue and research: an evaluation after 30 years of liberal metal detecting in archaeological research and heritage practice in Denmark", European fournal of Archaeology, Vol. 16 No. 4, pp. 704-725.

Elkington, S. and Stebbins, R.A. (2014), The Serious Leisure Perspective: an Introduction, Routledge, Milton Park, Abingdon, Oxon; New York, NY.

Hartel, J. (2010), "Managing documents at home for serious leisure: a case study of the hobby of gourmet cooking", foumal of Documentation, Vol. 66, pp. 847-874.

Holley, R. (2010), "Crowdsourcing: how and why should libraries do It?", D-Lib Magazine, Vol. 16, p. 18.

Jenkins, H., Purushotma, R., Weigel, M., Clinton, K. and Robison, A.J. (2009), Confronting the Challenges of Participatory Culture, Media Education for the 21st Century, The MIT Press, Cambridge, MA.

Jones, W.P. (2008), "Keeping found things found: the study and practice of personal information management", The Morgan Kaufmann Series in Multimedia Information and Systems, Morgan Kaufmann Publishers, Amsterdam; Boston.
Lewis, C.T. and Short, C. (1879), ămator, A Latin Dictionary, available at: www.perseus.tufts.edu/hopper/ text?doc $=$ Perseus \%3Atext $\% 3$ A1999.04.0059\%3Aentry\%3 Damator

Nourse, N., Insole, P. and Warren, J. (2017), "Having a lovely time: localised crowdsourcing to create a 1930s street view of Bristol from a digitised postcard collection", in Roued-Cunliffe, H. and Copeland, A.J. (Eds), Participatory Heritage, Facet, London.

OED Online (2016), Amateur, Oxford English Dictionary.

Oxford Living Dictionaries (2016), "Amateur - definition of amateur in English", Oxford Dictionaries | English, available at: https:/en.oxforddictionaries.com/definition/ amateur (accessed 28 November 2016).

Paulos, E. (2012), "You amateur! Interactions", $\underline{A C M}$ Interactions, Vol. 19, pp. 52-57.

Ridge, M. (2017), "The contributions of family and local historians to British history online", in Roued-Cunliffe, $\mathrm{H}$. and Copeland, A.J. (Eds), Participatory Heritage, Facet, London.

Ridge, M. (Ed.) (2014), Crowdsourcing Our Cultural Heritage, Ashgate, Farnham, Surrey.

Rojek, C. (2005), "P2P leisure exchange: net banditry and the policing of intellectual property", Leisure Studies, Vol. 24 No. 4, pp. 357-369, available at: https://doi.org/10.1080/ 0261436052000330438

Roued-Cunliffe, H. and Copeland, A.J. (Eds) (2017), Participatory Heritage, Facet Publishing, London.

Ruthven, I. and Chowdhury, G.G. (Eds) (2015), "Cultural heritage information: access and management", Facet Publishing, London.

Savolainen, R. (1995), "Everyday life information seeking: approaching information seeking in the context of 'way of life"', Librarv and Information Science Research, Vol. 17 No. 3, pp. 259-294.

Savolainen, R. and Kari, J. (2004), "Conceptions of the internet in everyday life information seeking", fournal of Information Science, Vol. 30, pp. 219-226, doi: 10.1177.

Simon, N. (2010), The Participatory Museum, Museum 2.0, Santa Cruz.

Skov, M. (2013), "Hobby-related information-seeking behaviour of highly dedicated online museum visitors", Information Research, Vol. 18 No. 4.

Stebbins, R.A. (1979), Amateurs, on the Margin between Work and Leisure, Sage, Beverly Hills.

Stebbins, R.A. (1982), "Serious leisure: a conceptual statement", The Pacific Sociological Review, Vol. 25 No. 2, pp. 251-272.

The British Museum (2016), "About the scheme", The Portable Antiquities Scheme, available at: http://finds. org.uk/about (accessed 12 January 2016).

UNESCO WHC (1972), "Convention concerning the protection of the world cultural and natural heritage", UNESCO World Heritage Centre, available at: http://whc. unesco.org/en/conventiontext/ (accessed 28 November 2016).

UNESCO (2016), "Definition of the cultural heritage", Illicit Trafficking of Cultural Property, available at: www.unesco. org/new/en/culture/themes/illicit-trafficking-of-culturalproperty/unesco-database-of-national-cultural-heritage- 
laws/frequently-asked-questions/definition-of-the-culturalheritage/ (accessed 28 November 2016).

Wohlin, C. (2014), Guidelines for Snowballing in Sustematic Literature Studies and A Replication in Software Engineering, ACM Press, New York, NY, pp. 1-10, doi: 10.1145/ 2601248.2601268.

Yakel, E. (2004), "Seeking information, seeking connections, seeking meaning: genealogists and family historians, genealogy, family history, information seeking, archives, personal information management", Information Research: An International Electronic fournal, Vol. 10 No. 1.

\section{About the author}

Henriette Roued-Cunliffe is an Associate Professor in Digital Humanities at the Royal School of Library and Information Science at University of Copenhagen, Denmark. She holds a DPhil from University of Oxford, UK, and has recently co-edited a volume on Participatory Heritage with Andrea Copeland. Her research focus has developed from archaeological computing to digital heritage with two research projects: Open Heritage Data and Participatory Heritage. Henriette Roued-Cunliffe can be contacted at: roued@hum.ku.dk

For instructions on how to order reprints of this article, please visit our website: www.emeraldgrouppublishing.com/licensing/reprints.htm

Or contact us for further details: permissions@emeraldinsight.com 